\title{
STUDIES OF THE SOLAR RADIATIONS' INFLUENCE ABOUT GEOMEMBRANES USED IN ECOLOGICAL LANDFILL
}

\author{
VASILUTA Petre \\ Engineer / PhD, SC Ecoman Solutions SRL, Craiova, Romania, e-mail: petrevasiluta@gmail.com \\ COFARU Ileana Ioana \\ Assistant professor / Ph.D., Faculty of Engineering/Computer Science and Electrical Engineering \\ Department, “Lucian Blaga” University of Sibiu, Sibiu, Romania, e-mail: ioana.cofaru@ulbsibiu.ro \\ COFARU Nicolae Florin \\ Professor / Ph.D., Faculty of Engineering/Industrial Engineering and Management Department, \\ “Lucian Blaga” University of Sibiu, Sibiu, Romania, e-mail: nicolae.cofaru@ulbsibiu.ro \\ POPA Dragos Laurentiu \\ Engineer/PhD, SC Ecoman Solutions SRL, Craiova, Romania, e-mail:dragospopa@gmail.com
}

\begin{abstract}
The study shown in this paper presents the behavior of geomembranes used at the ecological landfills. The influences of the solar radiations has a great importance regarding the correct mounting of the geomembranes. The mathematical model developed for the determination anytime and anywhere in the world for the next values and parameters: apparent solar time, solar declination, solar altitude, solar azimuth and incidence angle, zone angle, angle of sun elevation, solar declination, solar constant, solar flux density, diffuse solar radiation, global radiation, soil albedo, total radiant flux density and relational links of these values. The results of this model was used for creations an AutoCAD subroutines useful for choosing the correct time for correct mounting anywhere of the geomembranes
\end{abstract}

Key words: solar radiation, mathematical model, Auto LISP, geomembranes, ecological landfill, Auto CAD subroutine

\section{Introduction}

The use of geomembranes to the ecological landfill is recognized as a powerful and affordable solution compared to others methods. Lately, special attention is given to using materials that have a low impact on the environment. Installing geomembranes is safe for users, non-toxic, does not pollute, it is safe for the environment and for the human health. With a long life, they do not require frequent replacement [1].

The temperature which exist at the mounting of the geomembrane is a very important element because a high temperature lead at the inevitable appearance of the plies and these plies could have important consequences regarding the functioning and impermeability of the ecological landfill $[11,12]$.

Approximately $90 \%$ of the energy generated by the Sun in its central part is transmitted to the surface and then radiated into space through a series of complex radioactive and convective emission processes, absorption and subsequent radiation of different wavelengths in the spectrum continuous or discontinuous [2], [10],[13].

The objective of this study is to develop a software, working in AutoCAD, which can determine the evolution and the level of the solar radiation during a day in every place in world.

\section{Mathematical support}

2.1. Apparent movement of the Sun in the sky

The sun performs an apparent rotation in the sky with an angular velocity: $\omega=\pi / 12 \mathrm{rad} / \mathrm{h}=15$ $\mathrm{dgr} / \mathrm{h}$. The sun's position in the sky is determined by the angle $\mathrm{H}$ and elevation angle $\mathrm{h}$. The angle $\mathrm{H}$ is 
measured around the pole axis between the meridian plan of the place and circle meridian zone of the star. The simplifying assumption that solar time is equal to the meridian legal ground time, the angle zone is calculated with:

$$
H=(\pi / 12) *\left(\tau-\tau_{0}\right)
$$

In (1) the meanings of the values are: $\tau$ - legal time, $\tau_{0}$ - time of the meridian passage of the sun, $\mathrm{H}$-angle zone.

Sun elevation angle from the horizontal plane of the ground is:

$\sinh =\sin \lambda \sin \partial+\cos \partial \cos \lambda \cos H$

In relation (2) we have:

- Value $\lambda$ is the latitude of the place, for approximate calculations can be considered a value $\lambda=$ $45^{\circ}$ (for Bucharest $\lambda=44.3954^{\circ} \lambda=44.26969^{\circ}$ and Craiova, Sibiu $\lambda=45.779887^{\circ}$ );

- Value $\delta$ is declination, the angle measured between the Sun and the equatorial plane:

$$
\delta=23.4 \sin \left[\frac{2 \pi(284+N)}{365}\right]
$$

Where $\mathrm{N}$ is the Julian day, that means the day of the year counted from January 1, with the following equation:

$$
N=30.416(\chi-1)+n
$$

where $\chi$ indicates the month and $\mathrm{n}$ indicates the day of month [6].

\subsection{Solar constant}

The amount of solar energy to upper Earth's atmosphere, pass through a unit area normal to the direction of propagation of the unitary time I called global solar radiation intensity is:

$$
I=\frac{4 \pi r^{2} \sigma T^{4}}{4 \pi d^{2}}
$$

Earth-Sun distance variation causes changes for the value of I from day to day. Measurements of N.A.S.A. indicates the intensity variation between the limits $1310 \mathrm{~W} / \mathrm{m} 2$ (June) and $1400 \mathrm{~W} / \mathrm{m} 2$ (January). $1367 \mathrm{~W} / \mathrm{m} 2$.

Annual average solar radiation in the upper atmosphere is called the solar constant $\mathrm{S}_{\mathrm{Sn}}=$

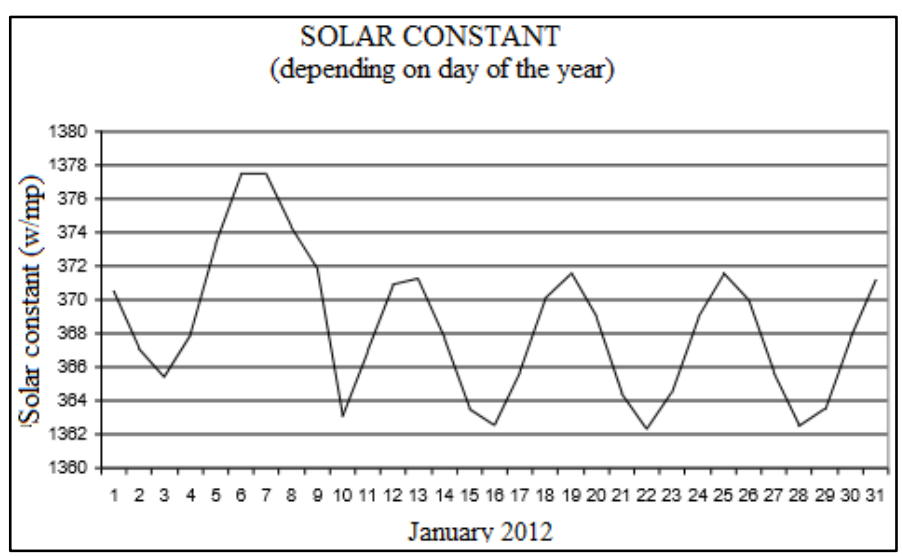

Figure 1: The solar constant S during January 2012

For the $\mathrm{N}$ day of the year, the solar constant correction (Figure 1) is calculated as [6]:

$$
S=S_{s n}(1+0.0034 \cos N)
$$

\subsection{Radiant flux density on the soil}

When crossing the Earth's atmosphere by solar radiation, attenuation occurring phenomena are leading radiant flux density. These phenomena are: a fraction of radiation energy absorbed by the gas components of the atmosphere, molecular diffusion and Rayleigh scattering

Helpful Hints by aerosols. On the ground radiation has two components: the direct component 
attenuated and the diffuse component. On these components is added albedo ground reflected radiation.

Direct component of solar flux density B on soil calculated on a surface normal to the sun, under a clear sky, is:

$$
B=S \cdot a \cdot e^{\left(-\frac{b}{\sinh }\right)}
$$

Where value " $a$ " depends by the place characteristics and value " $b$ " depends by the influence of attenuators. For a given position these values can be considered: $a=0.88$ and $b=0.28$.

Value $\mathrm{D}$, the diffuse component of solar radiation is:

$$
\mathrm{D}=\mathrm{S} \cdot\left[0.2710-0.2939 \mathrm{a} \cdot \mathrm{e}^{\frac{-\mathrm{b}}{\sinh }}\right] \cdot \sinh
$$

Substituting relation (6) of solar constant $\mathrm{S}$ in (8) we obtain:

$$
D=S_{s n}(1+0.0034 \cdot \cos N) \cdot\left[0.2710-0.2939 a \cdot e^{\frac{-b}{\sinh }}\right] \cdot \sinh
$$

Total radiant flux density on a horizontal surface is called irradiance or global radiation G:

$G=B \sinh +D$

Soil albedo is:

$$
(A b)=\frac{r \cdot B \cdot \sin h}{2}
$$

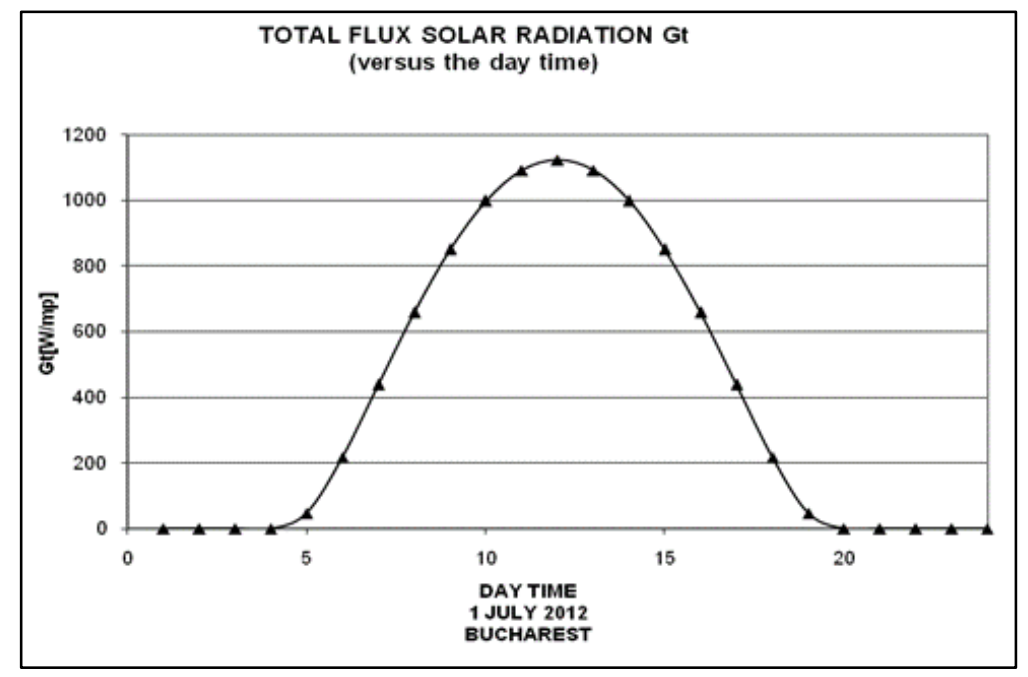

Figure 2: Total radiant flux density calculated on 1st of July 2012 in Bucharest

Where, for local conditions, $r=0.55[6]$.

Total radiant (Figures 2) flux density is:

$$
G t=G+(A b)
$$

3. Software for calculus of the total solar radiation for anytime and any geographical position 
ACTA UIVERSITATIS CIBINIENSIS - TECHNICAL SERIES

Vol. LXIX 2017

In this chapter is shown the steps which were followed in order to develop Auto Lisp program $[7,8]$. The main objective of the software is to calculate the total solar radiation for anytime and any geographical position.

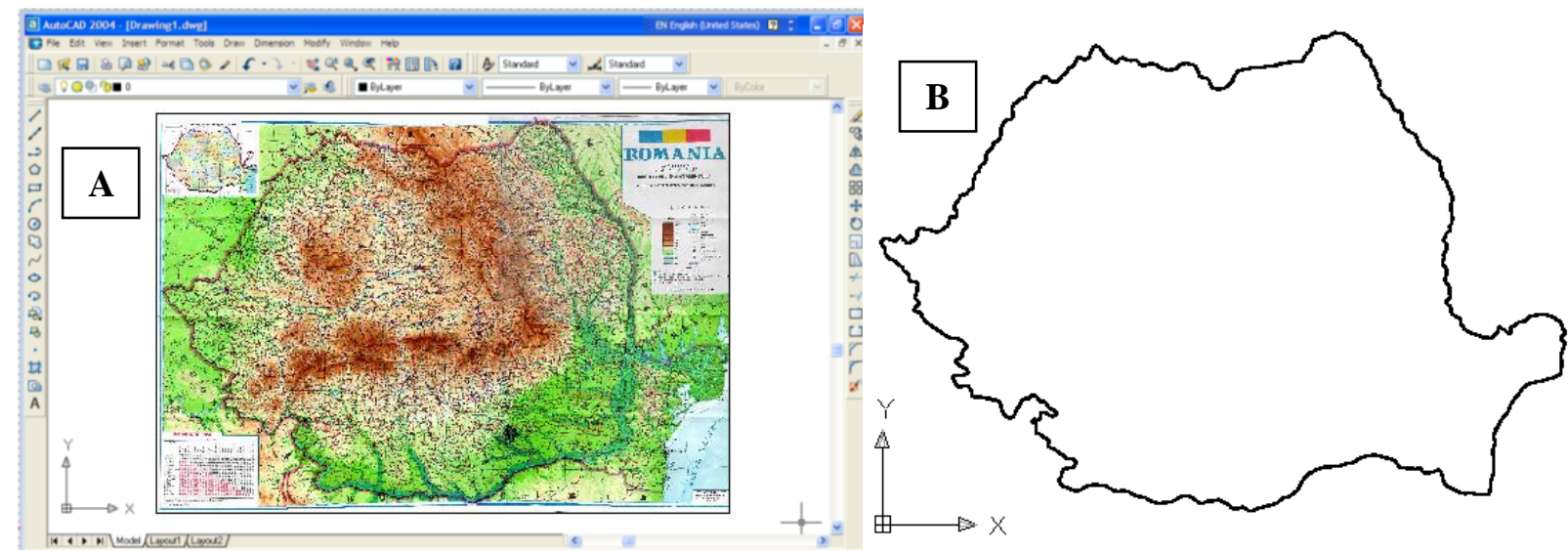

Figure 3: A - Romania map loaded in AutoCAD; B - The drawing of the borders of the map and the approximation Spline curves

In AutoCAD is loaded a map of Romania (Figure 3A) that has been scaled using scale grid so that 1 unit is equal to $1 \mathrm{~km}$ and over the map, the contour of the Romania map using PLINE command was drawn. This outline was processed turning straight lines into Spline segments (Figure 3B). Then, over contour map were drawn parallels and meridians approximated by straight lines and arcs (Figure 4A) and at the intersection of meridians, approximated by straight lines was determined the geographic North Pole position. On the virtual map the main cities of Romania were positioned (Figure 4B);
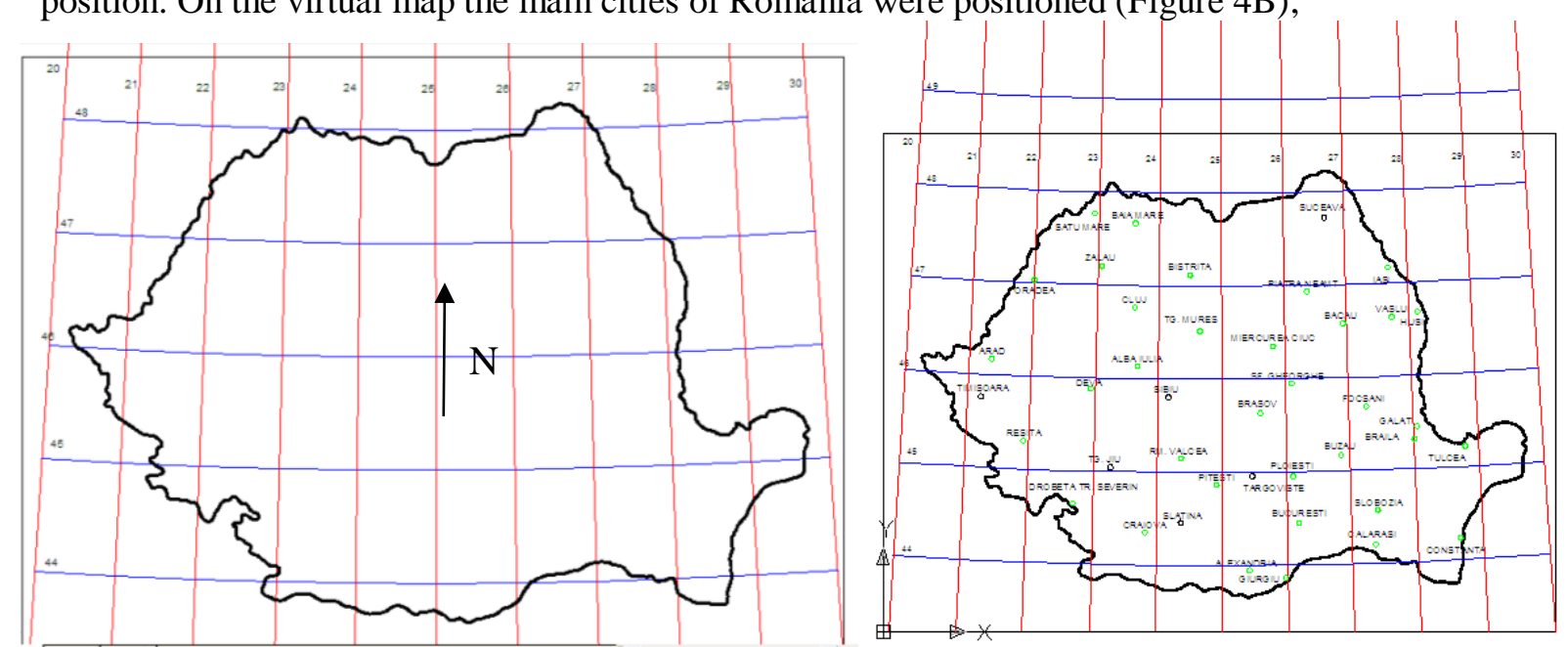

Figure.4. A - The drawing of the parallels and meridians; B - The main cities on the virtual map

After the positioning of the main graphical entities core values, the important values necessary to write Auto LISP code were obtained:

- Distance between two parallel on a meridian:

$\Delta \mathrm{r} /{ }^{\circ} \mathrm{lat}=113.5399 \mathrm{~km} /{ }^{\circ}$ latitude

- Value in geometrical degrees for a degree of longitude:

$\Delta$ long $=0.745^{\circ} \%$ longitude

Using these two values and the reconstructed map in AutoCAD, following calculation subroutines were obtained:

- Subroutine which, from the location given by latitude and longitude, the system determines the Cartesian 


\section{ACTA UIVERSITATIS CIBINIENSIS - TECHNICAL SERIES}

Vol. LXIX 2017

coordinates reported to the fixed coordinate system on the virtual map;

- Subroutine that takes the coordinates of a location on the map and turn them into geographic coordinates expressed in degrees of latitude and longitude;

- Subroutine that calculates the total solar radiation from latitude and longitude location and the date on which the calculation is made.

The core calculation was completed with the following subroutines:

- Code sequence of predefined locations calculation that calculates the total radiation for values $\mathrm{x}, \mathrm{z}$ Cartesian values reported to the fixed coordinate system located in the lower left corner of the map;

- Code sequences for the determination of distances between two points on the maps or between a location and the geographic North Pole.

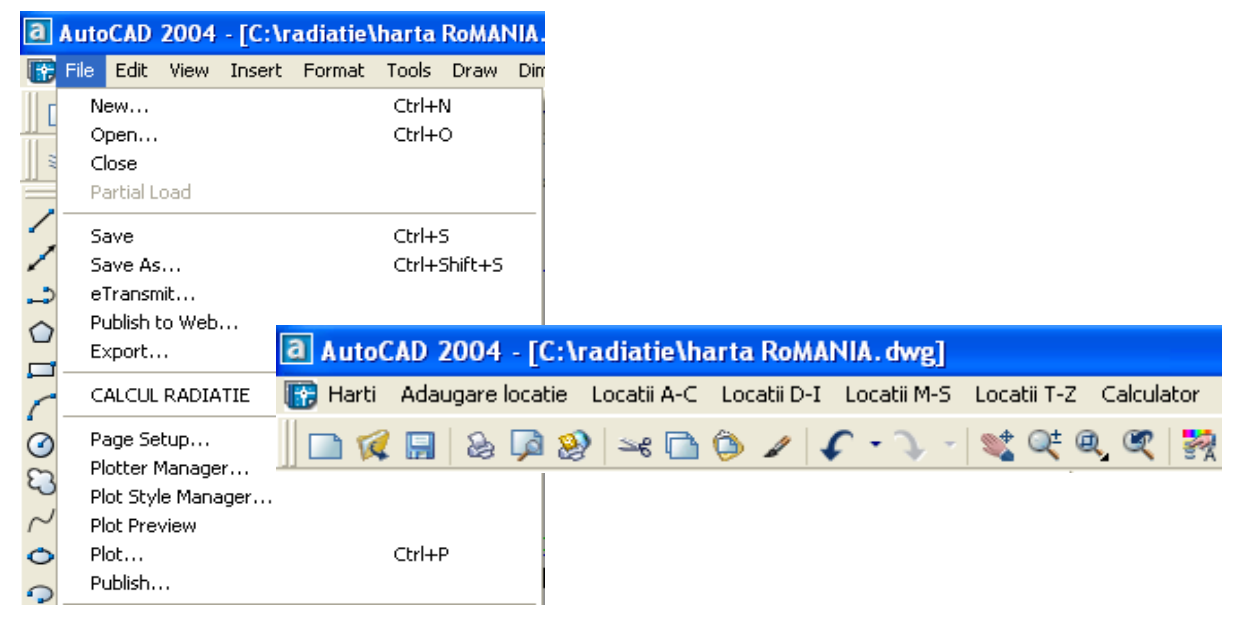

Figure.5. - AutoCAD - personalized menu for calculus of the solar radiations

These subroutines are called from a pull-down menu stored in a .mnu file, which allows direct loading by displaying a custom menu. Also, the AutoCAD menu (acad.mnu file) was modified to allow direct access to the program for the calculation of total radiation by pressing a radio button. As we can to observe the button "radiation calculus" (calcul radiatie) has included as distinct button in menu "File" from Auto CAD. The submenu which appear after pushing the button has facilities such as: Maps (Harti), Add new location (Adaugare locatie) or input the existent locations grouped in letters intervals (A-C, DI, M-S, T-Z).

The input data are "the location" and period of time where the geomembrane installation is desired. The obtained results after running the software are shown as a suggestive diagrams. Each diagram is related to a day of the studied period and the total solar flux density is evaluated at any time. 
In the following figures are shown the diagrams regarding total solar radiation in Bucharest in every first day of the odd month of the 2012 year. These results was obtained with the designed software.

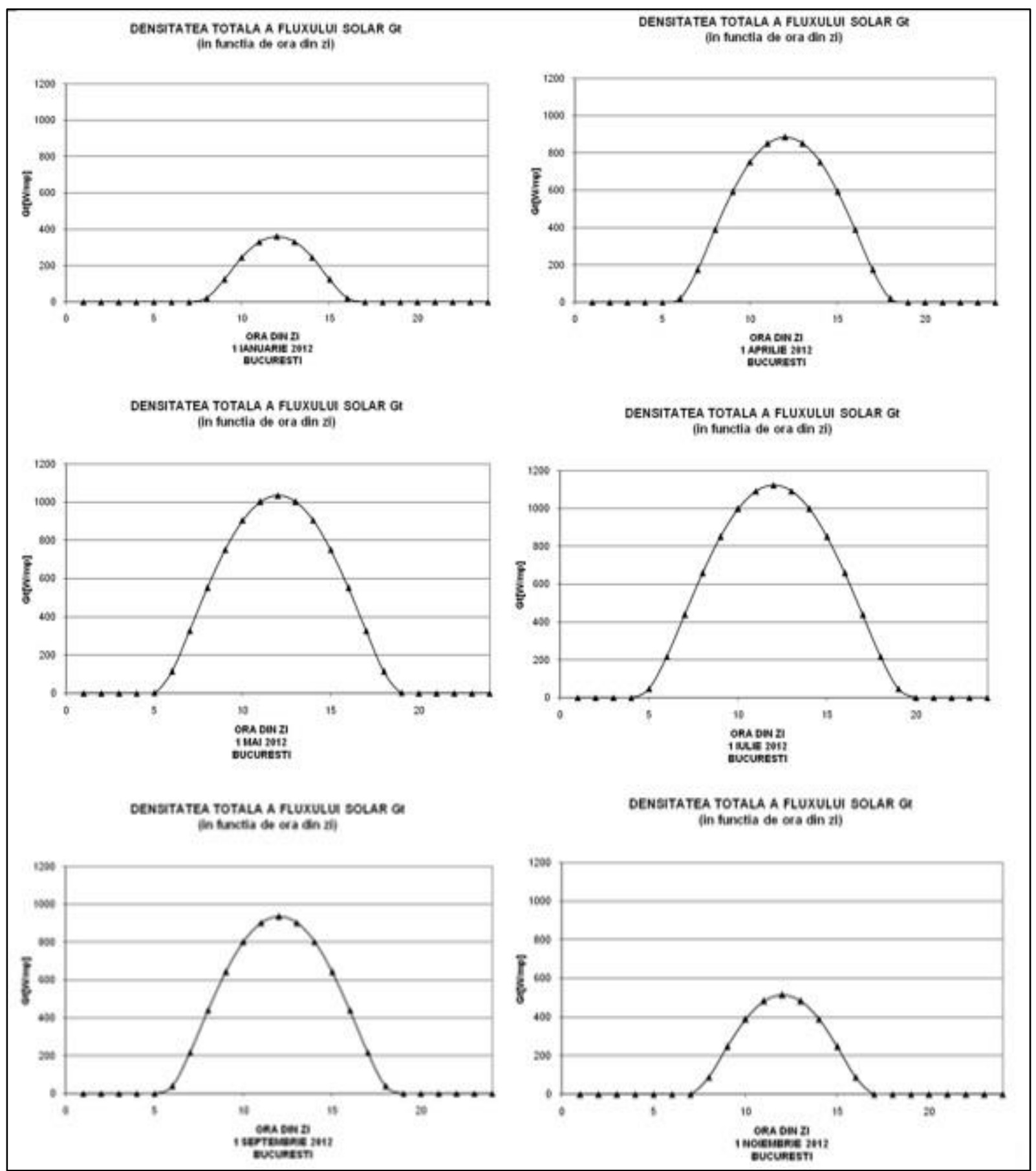

Figure 6. - Diagrams regarding total solar radiation in Bucharest in every first day of the odd month of the 2012 year

\section{Conclusions}

Personal contributions have made a theoretical significance but also a strong practical. Such mathematical modeling carried out on the calculation of the density of the total radiant flux at a certain day, hour to a location once formed the basis of achievements with software Auto LISP an application computerized calculation of the total solar radiation at the time and location determined by user to obtain 


\section{ACTA UIVERSITATIS CIBINIENSIS - TECHNICAL SERIES}

Vol. LXIX 2017

the best strategy of installing the membrane.

A new further research could been the study of the temperature's gradient of the geomembrane using Finite Elements Method. Numerical studies on membrane behavior after its surface temperature variation emphasize the important role of environmental conditions while installation.

As we know, the geomembranes, used for ecological landfill during the assembly process, are exposed to the sun radiation. These elements due to thermal expansion may be folded the geomembranes. The plies which appear in exploitations could damage the geomembrane with bad consequences on the good functioning and on the non-permeability of the ecological landfill.

In that case, the program presented in this paper can be a good tool for the evaluation of the total solar radiation flux during the assembling process. Also, this program can be installed on a mobile computer and the initial data can be obtained from a GPS device.

We consider that the study is very important in order to achieve a good and correct mounting of the geomembrane.

\section{References}

1. Barbulescu, D., Research on membrane protecting the dam from local materials against infiltrations, $\mathrm{PhD}$ Thesis, Technical University of Civil Engineering, Faculty of Hydrology, Bucharest, (2011).

2. Danescu, A., Bucurenciu, S., Petrescu, S., Using solar energy, Technological Publishing House Bucharest, (1980).

3. Dickinson, S. J. E., Physical Response of Composite Geomembrane/Geosinthetic Clay Liners under Simulated Landfill Conditions, PhD Thesis, Queen's University, Kingston, Ontario, Canada, (2008).

4. Giroud, J. P., Badu-Tweneboah, K., Soderman, K.L., Theoretical Analysis of Geomembrane Puncture, Geosynthetics International, vol.6, (pp.1019-1048), (1995).

5. Kwang, Y.L., Chin, G. C., Taik, J.H, Seong,H.Y, The Stress-Strain Behavior of Geotextiles under Puncture Loads in a Liner System, Proceedings of The Twelfth International Offshore and Polar Engineering Conference, Kitakyushu, Japan, (2002).

6. Luminosu, I., Rate of thermal solar systems, Faculty of Electrical Engineering, University "Politehnica" of Timisoara. (2009)

7. Popa, D., Gherghina, G., Tutunea D., Computer Aided Graphics for construction. Drawing, modeling, programming, Ed. Sitech, ISBN 978-606-530-726-1, Craiova, (2009).

8. C. Stancescu, Autolisp Programing manual, Fast Publishing House Bucharest (2000).

9. Hamid S., Mohammad T.R., Geosynthetic day liners shrinkage under simulated daily thermal cycles, Waste Management \& Research, (2014).

10. Pelte T, Pierson P., Gorc J.P., Thermal analysis of geomembranes under the effect of solar radiation, Geosynthetics International, vol. 1, p.21-44, (1994).

11. Rayhani M.T., Row R.K., Brachman R.W.I, Factors affecting GCL hydration under isothermal conditions. Geotextiles and Geomemrbanes, vol. 29, p. 525-533, (2011).

12. Take W.A., Watson, Brachman E., Rowe R.W.I., Thermal expansion and contraction of geomembrane liners subjected to solar exposure and backfilling, J. Geotechnical Geoenvironmental Eng., p. 1387-1397, (2012).

13. OLEKSIK, V., PASCU A. Proiectarea optimală a maşinilor şi utilajelor, Editura Universităţii „Lucian Blaga" din Sibiu, ISBN 978-973-739-431-6, (2007). 